\title{
NOVA TENDÊNCIA DO FOTOJORNALISMO: FOTO DE OBAMA COMO REFERÊNCIA
}

\author{
Maria Ogécia Drigo ${ }^{1}$ \\ Celene Maria dos Santos ${ }^{2}$
}

\section{Introdução}

Neste artigo, partimos do pressuposto que as mídias são relevantes para a vida social. Compartilhamos as ideias relativas às tendências culturalistas dos estudos comunicacionais, que consideram as mídias vinculadas à vida social e que, a partir dos anos 70 do século XX, passaram a agregar também estudos referentes à contemporaneidade. Nesses estudos, os meios de comunicação encontram uma lógica de desenvolvimento que lhes é própria e que não se desvincula da cultura. Estudos sobre a produção de sentidos de imagens fotojornalísticas se inserem nessas tendências, uma vez que esse processo de construção contribui para reorganizar ou realimentar práticas sociais.

Assim, o fotojornalismo é o tema destas reflexões que objetivam conjeturar sobre aspectos de uma possível e nova tendência do fotojornalismo, a partir de análise da foto de Barack Obama, vencedora do Prêmio Pultizer ${ }^{3}$, em 2009, da série Following Obama, de Damon Winter, composta por fotos realizadas durante a campanha do candidato à presidência dos Estados Unidos, em 2008. Para tanto, examina-se tendências reinantes no fotojornalismo e avalia-se o potencial de significados, a partir da análise semiótica, na perspectiva peirceana, da foto mencionada. Valemo-nos de Sousa $(1998 ; 2000 ; 2002)$, entre outros autores, para tratar das tendências do fotojornalismo, enquanto a análise é permeada por especificidades do imaginário americano, segundo Wunenburger (2007).

\footnotetext{
${ }^{1}$ Pontifícia Universidade Católica de São Paulo, Brasil.

${ }^{2}$ Universidade de Sorocaba, São Paulo, Brasil.

${ }^{3}$ O Prêmio Pulitzer é outorgado às pessoas que realizam trabalhos de excelência na área do jornalismo, literatura e música. É administrado pela Universidade de Colúmbia, de Nova Iorque. Foi criado em 1917, por desejo de Joseph Pulitzer, que por ocasião da sua morte fez donativos à Universidade de Colúmbia. Parte dessa doação foi revertida para a criação do curso de jornalismo, em 1912. Apenas matérias e fotografias publicadas por jornais nos Estados Unidos são eligíveis pelo prêmio de jornalismo.
} 
A análise das fotos, fundamentada na semiótica peirceana, como consta de Santaella (2002), bem como em Drigo e Souza (2013), elenca aspectos qualitativos, referenciais e aqueles compartilhados culturalmente, como regras, convenções, engendradas na imagem e inventaria, a partir destes aspectos, os possíveis efeitos: emocionais, reativos e aqueles que levam à reflexão. Exibimos possíveis interpretações, ou seja, inventariamos o potencial de sentidos latente na foto, que podem ser agregados à imagem de Obama. Assim, apresentamos, inicialmente, especificidades das imagens fotojornalísticas e, em seguida, a análise da foto selecionada.

\section{O fotojornalismo em foco}

A figura do fotógrafo pode ser associada à do caçador, ou seja, ela lembra "o antiquíssimo gesto do caçador paleolítico que persegue a caça na tundra. Com a diferença de que o fotógrafo não se movimenta em pradaria aberta, mas na floresta densa da cultura" (Flusser, 1985: 35).

Esse caçador não é passivo, pois há um processo de construção da realidade no fotográfico, conforme kossoy (2000), que envolve, entre outras especificidades, o assunto que é objeto de registro, a tecnologia que o viabiliza, bem como o fotógrafo com todo seu repertório pessoal. A fotografia subtende espaços e tempos específicos com desdobramentos sociais, econômicos, culturais e registra, de certo modo, um filamento deste contexto e sempre foi utilizada, nos jornais, como prova para os fatos, que conquistou credibilidade pela sua capacidade de registrar aspectos do real. Assim, não é, portanto, espelho do real, mas exibe marcas, vestígios dele. "A imagem fotográfica fornece provas, indícios, funciona sempre como documento iconográfico acerca de uma dada realidade. Trata-se de um testemunho que contém evidências sobre algo" (Kossoy, 2000: 33).

O fotojornalismo, para Sousa (2000), no sentido lato, corresponde à produção de fotografias informativas, interpretativas, documentais ou ilustrativas destinadas à imprensa ou a projetos editoriais para produção de informação da atualidade. Neste sentido, a prática do fotojornalismo envolve spot news, fotografias de grandes reportagens e de fotodocumentários, de modo geral, onde as finalidades são priorizadas em detrimento da intenção do fotógrafo e dos aspectos do produto final. No sentido 
restrito, o fotojornalismo corresponde à "atividade que pode visar informar, contextualizar, oferecer conhecimento, formar, esclarecer ou marcar pontos de vista (opinar) através da fotografia de acontecimento e da cobertura de assuntos de interesse jornalístico" (Sousa, 2000:12).

Os caminhos do fotojornalismo, por sua vez, conforme Persichetti (2006), pode ser compreendido se considerarmos dois momentos diferentes: o primeiro deles dado pelas fotografias de grandes revistas como Life e Paris Match; o segundo, dado por uma estética que se aproxima da estética da ilustração. Assim, de modo geral, o trabalho do fotógrafo como "contador de história", via imagens, deu lugar à fotografia-choque e, finalmente, nos anos de 1990, a fotografia passa a exibir uma estética publicitária ou cinematográfica. "Não mais o impacto da imagem ou o horror que interessam, mas luzes e sombras, a dramaticidade construída por uma estética vazia. (...) existe o drama; a viúva jogada por sobre o corpo do marido, a mãe madonna que chora o filho..." (Persichetti, 2006: 184).

Vejamos especificidades de fotografias premiadas, pois para Sousa (1998), o fotojornalismo é uma atividade que pode ser compreendida e descrita também com o estudo de fotografias premiadas em concursos nacionais e internacionais, pois a natureza delas pode dar a trajetória do fotojornalismo, bem como mostrar aspectos qualitativos pertinentes à fotografia jornalística.

Entre resultados de uma pesquisa realizada por Sousa (1998), ele destacou o trabalho de Stephen Plunkett, em 1975, da Universidade do Tennessee. Da análise de 35 fotografias que receberam o prêmio Pulitzer, o pesquisador constatou a presença de oito temas: distúrbio, violência, segurança, necessidades humanas, ameaças, idolatria, salvamento de morte e excentricidades e singularidades. Em 1984, Lichel Singletary e Chris Lamb concluíram, em pesquisa realizada com fotografias vencedoras da National Press Photografers Association, que $81 \%$ das fotografias vencedoras na categoria spot news e de features tratavam de acidentes, desastres, crimes e violência. Em 1992, um estudo realizado por Evelyne J. Dych e Gary Coldevin enfatizou a eficácia de reportagens que se valiam de imagens que transmitiam sensações agradáveis, alegres. 
Sousa (1998) destaca que na recepção de mensagens escritas e de mensagens que articulam escrita e fotografia, de modo geral, as fotos enriquecem informativamente os enunciados verbais e as mensagens com fotos, atraem mais a atenção e são as preferidas na leitura. As pessoas gostam de fotografias, em especial, das coloridas. Salienta ainda que as imagens fotográficas podem construir um contexto, o frame de uma estória, que pode facilitar a compreensão e manter o interesse do intérprete.

Em pesquisa realizada com quarenta "Fotos do Ano", da World Press Photo, de 1956 a 1995, Souza (1989) explicitou os valores-notícia que as fotografias apresentavam, ou seja, tratou dos critérios de noticiabilidade, do que faz com que um fato ou acontecimento, na perspectiva midiática, venha a ser noticiado. Das análises destacamos os seguintes resultados: $87,5 \%$ das fotos podem ser classificadas como fotos-choque e $92,5 \%$ desviam-se para a negatividade, enquanto três delas apresentaram valor emotivo ou emocional; tensão é um valor presente em $95 \%$ das fotos; pessoas mortas ou feridas vêm em $35 \%$ delas e $5 \%$ delas apresentaram pessoas públicas como protagonistas. As fotos premiadas apresentaram ainda convergência temática, sendo que a violência foi o tema predominante. A convergência nos enquadramentos, com dominância de planos médios; convergência na cor, sendo que as coloridas predominaram e a questão da "oportunidade", da captura de um momento decisivo de uma ação ou acontecimento também predominaram.

Com esta pesquisa, Sousa (1998) conclui que os critérios de noticiabilidade valorados se referem aos valores-notícia tradicionais. Somente uma fotografia foi premiada devido ao seu caráter estético. Assim, a intensidade confere valor como notícia para fotografias de acontecimentos. As figuras públicas apareceram em apenas $5 \%$ das fotos, o que o levou a inferir que a proeminência social, considerada como normal para os órgãos da comunicação social, não vem como valor para essa modalidade de imagem. O momento decisivo de uma ação ou acontecimento; a tensão e a ação que geram conflito, bem como a negatividade, embora não seja exclusivo do fotojornalismo são privilegiados. A emoção também pode ser considerada um valor, principalmente quando vinculada à negatividade. 
Para Sousa (1998), a hegemonia das representações da violência se explica pela submissão da fotografia ao horror, à exploração do tabu da morte como luta comercial num ambiente de concorrência deflagrado pela concentração dos meios de comunicação. Essa contribui para o aumento do sentimento de insegurança entre os observadores. A influência histórica ainda é forte, pois está vinculada às raízes do fotojornalismo. Por sua vez, o enquadramento predominante revela a objetividade e a manutenção pela visão da fotografia como "espelho do real", por parte dos fotojornalistas. A revalorização do preto e branco no fotojornalismo, em fotos de 1992, 1993, 1994 e 1995, parece ir ao encontro de intervenções de acadêmicos que rompem com práticas rotineiras e que promovem uma reaproximação do fotojornalismo à arte.

As fotos premiadas, do período de 1997 a 2011, confirmam as tendências mencionadas por Sousa (1998). A maior parte das fotos apresentadas são "fotos-choque" 4 e poucas exploram valores emotivos ou envolvem figuras públicas.

Vejamos a análise da foto vencedora do Prêmio Pulitzer, em 2009, após mencionarmos aspectos da relação entre imagem e imaginário.

\section{O potencial de sentidos latente na foto de Obama}

O imaginário pode ser compreendido como uma modalidade de força, de tecido qualitativo capaz de ser aguçado na semiose - ação do signo - e assim propiciar associações e conexões de signos/interpretantes na mente do intérprete num processo interpretativo. A semiose depende também da experiência colateral ou conhecimento colateral do objeto pelo intérprete. Nas palavras de Peirce (CP 2.231):

Contudo, se houver alguma coisa que veicule informação e, apesar disso, não tenha absolutamente relação nem faça referência a algo com o qual a pessoa a quem a informação é transmitida tenha a menor familiaridade, direta ou indireta, quando recebe a informação - informação que seria de uma espécie estranhíssima -, o veículo desse tipo de informação não será, neste contexto, denominado Signo.

\footnotetext{
${ }^{4}$ As fotos-choque, de modo geral, podem preponderar, na perspectiva da semiótica peirceana, como sinsignos indiciais, cujos efeitos ou interpretantes podem ser remáticos ou dicentes, ou seja, o efeito tanto pode ser uma expressão de espanto ou uma reação, como o gesto de desviar o olhar da foto, o que significa que ela não se faz símbolo, não desencadeia a semiose, ou ação da foto, como símbolo. Isto não contradiz as análises de Barthes, embora com pressupostos distintos dos da semiótica peirceana, para quem a "fotografia traumática (incêndios, naufrágios, mortes violentas captadas "ao vivo") é aquela de que não há nada a dizer: a foto-choque é por estrutura insignificante” (Barthes, 2009, p. 26).
} 
No caso, conhecimentos relativos à trajetória política de Obama, especificidades históricas dos Estados Unidos, ou mesmo o fato de que Obama seja identificado são importantes para que a imagem fotográfica desencadeie um processo interpretativo. Mas, esses conhecimentos ganham maior vivacidade em decorrência também do imaginário do intérprete. $\mathrm{O}$ fato de o intérprete ser cidadão americano - e todo o potencial do imaginário desse povo estar nele presente, pois o imaginário é coletivo interfere no processo interpretativo.

Imagens e imaginário estão vinculados. Dentre as formas de expressão do homem, segundo Wunenburger (2007), há a experiência do olho, escópica, que constrói representações analógicas dos objetos; de outro lado, a voz que, originalmente ligada à experiência da verbalização, substitui o real pelos signos convencionais e abstratos da língua. No entanto, dificilmente a palavra pode dar conta do êxtase visual que uma imagem propicia. Ela coloca o sujeito numa posição de visão panorâmica, sinótica, na qual tudo ocorre, ao menos à primeira vista, de maneira instantânea. Para Wunenburger (2007: 29), a "imagem visual enriquece mais o imaginário individual ou coletivo do que os atos e as obras da linguagem".

O imaginário, portanto, é uma construção coletiva e parte da cultura. Conforme Maffesoli (2001:75):

A cultura pode ser identificada de forma precisa, seja por meio de grandes obras, no sentido restrito do termo, teatro, literatura, música, ou, no sentido amplo, antropológico, os fatos da vida cotidiana, as formas de organização de uma sociedade, os costumes, as maneiras de vestir-se, de produzir, etc. O imaginário permanece uma dimensão ambiental, uma matriz, uma atmosfera.

O imaginário perpassa todos os domínios da vida e alcança mesmo as searas da política, da ideologia e da economia. Para Maffesoli (2001: 78), cada vez mais a persuasão se faz via sedução, ou o convencimento vem pela emoção; assim sendo "o imaginário político trabalha a argumentação através de um arsenal de mecanismos emocionais, como os símbolos de um partido, as datas que devem ser comemoradas, os heróis em ritos que devem ser lembrados, os ritos que precisam ser atualizados". 
O imaginário de um indivíduo é muito mais grupal, comunitário, tribal ou mesmo partilhado. "Partilha-se uma filosofia de vida, uma linguagem, uma atmosfera, uma ideia de mundo, uma visão das coisas, na encruzilhada do racional e do não racional" (Maffesoli, 2001: 80). Nesse sentido, também caminham as seguintes considerações de Wunenburger (2007: 45):

(...) os enunciados e quadros de um imaginário veem-se substituídos e modificados pelas referencias coletivas (dogmas religiosos, credos políticos, crenças coletivas sobre a história, ideologias sociais etc.) que atuam conferindo-lhes uma credibilidade e uma autenticidade suplementares. O imaginário de um indivíduo é, por exemplo, inseparável dos grandes símbolos e mitos políticos que modelam suas representações do território nacional, da instituição do poder, das transformações sociais etc. A articulação entre esses dois níveis de imaginário ilustra, por conseguinte, uma dialética entre imaginário partilhado e imaginário privado.

O imaginário quer esteja vinculado a uma obra de arte, ou seja, o imaginário de um criador, de um povo, ou mesmo de uma época, não constitui um conjunto anárquico, caótico, que faz associações de imagens sem seguir regra alguma, pelo contrário, segue estruturas e conhece uma história marcada por um jogo sutil de constantes e de variações no tempo. Isso pode ser visto se buscarmos, por exemplo, o imaginário americano, que para Wunenburger (2007), perpassa uma religiosidade messiânica, uma política puritana e um materialismo hedonista. Vejamos os vínculos com o imaginário que a imagem fotojornalística pode reavivar.

Iniciamos a análise semiótica da foto (Figura 1) elencando os aspectos qualitativos e os possíveis efeitos provocados num intérprete. Os tons amarronzados, que compõe o plano de fundo, podem ser associados, conforme Farina (2000), à melancolia, à resistência, ao vigor, enquanto a cor preta é expressiva e torna-se alegre ao ser salpicada com pontos iluminados. Por sua vez, a luz que vem como uma nebulosa acentua tal caráter e confere à pessoa iluminada, para algum intérprete, a impressão de que ela é inatingível. 


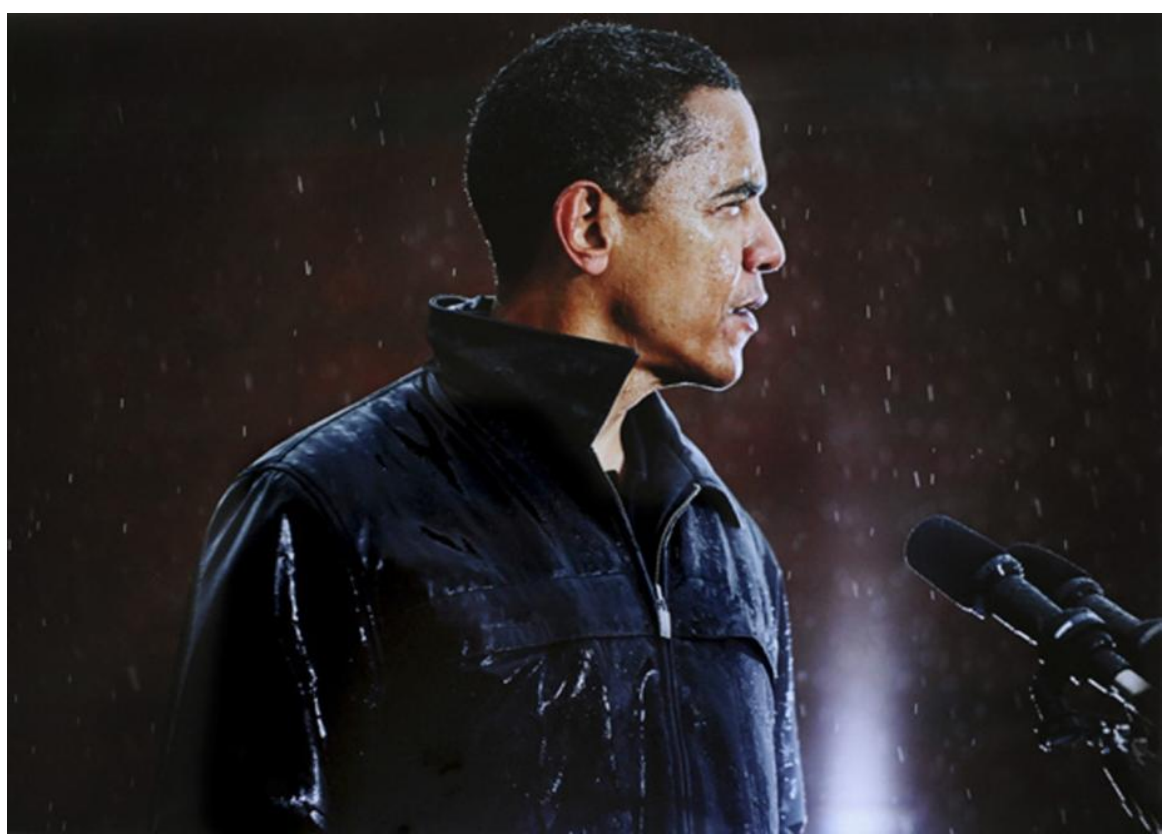

Figura 1- Reprodução de uma foto do Senador Obama sob a chuva durante a campanha na Universidade em Widener, na cidade Chester, Pa. (Damon Winter, 2008)

Fonte - Disponível em: 〈http://www.pulitzer.org/citation/2009-Feature-Photography>. Acesso em: 10 ago. 2010.

Os contornos dos ombros, do tronco, rosto e cabelos se destacam com o efeito da luz, a pele adquire um brilho opaco, aquoso, dando ao corpo uma aparência de estátua. Próximo ao corpo vem um tom azulado. A bandeira dos Estados Unidos se faz presente, se insinua neste tom. Esses aspectos qualitativos mencionados, que desencadeiam analogias, comparações, podem levar o intérprete a considerar a pessoa presente na foto - Obama - como alguém poderoso, capaz de enfrentar dificuldades, de não se abalar diante de intempéries. Esses atributos podem ser incorporados à imagem de Obama.

Seguem os aspectos referenciais, ou seja, segue a descrição da imagem fotográfica e, em seguida, destacam-se elementos que podem remeter o intérprete a outros contextos. A foto apresenta, em primeiro plano, um homem de perfil - Obama -, que veste uma jaqueta preta de couro. A foto toma a parte superior do corpo, acima do tórax, como um busto. O segundo plano é constituído por uma tonalidade de marrom que se aproxima do negro, em algumas partes, salpicado de pontos luminosos, gotas d'água. A luz se concentra no corpo de Obama ou permanece condensada entre o seu corpo e os microfones, como uma fonte de luz, uma nebulosa. 
Passemos ao contexto da foto ou seu aspecto singular. A luz ao fundo permite imaginar uma distância razoável entre Obama e o público que deve estar sentado em fileiras não identificáveis no plano de fundo. Este efeito faz crer que Obama esteja em um plano elevado, talvez um púlpito, que seria uma espécie de plataforma, possibilitando sua visibilidade a partir de qualquer ponto do ambiente onde ele se encontra. A constatação - Obama em campanha política - é um dos efeitos possíveis também.

A gola aparentemente desajeitada indica certa displicência, uma característica da juventude rebelde, imagem da juventude construída pelo cinema americano. Em 1953, Hollywood lançou o filme The Wild One (O Selvagem), protagonizado por Marlon Brando, no papel de Johnny, um motoqueiro rebelde, líder de uma gangue de motoqueiros (Figura 2). Esses jovens usavam jaqueta de couro, jeans, coturnos. A jaqueta de couro, de modo geral, nos remete à juventude e ao universo hollywoodiano.

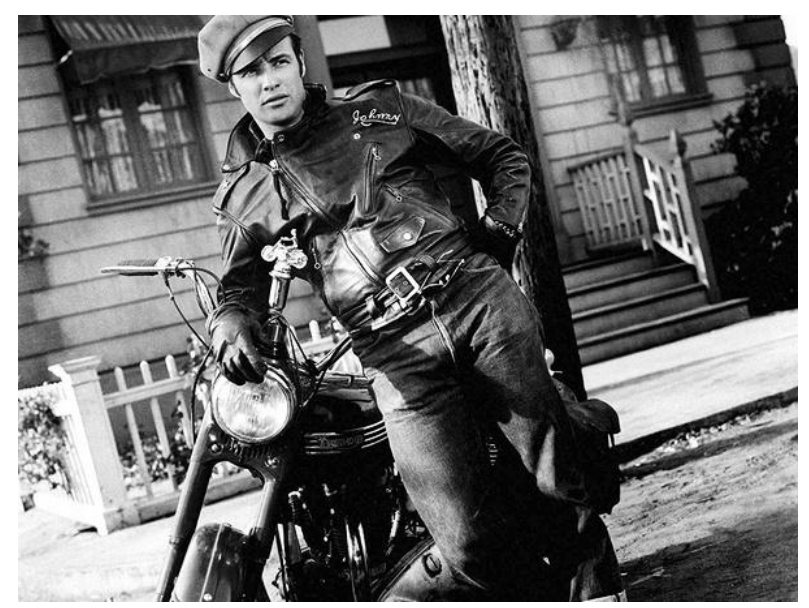

Figura 2 - Reprodução de uma foto de Marlon Brando. Fonte: Disponível em:

$<$ http.justlia.com.br/wp-content/uploads /2010/04/jaqueta de courooo1.jpq>.Acesso em: 5 jun. 2012.

Nos anos de 1890, segundo Savage (2009), a sociedade dos Estados Unidos assistiu ao início de uma profunda mudança de valores, com a troca da salvação protestante no outro mundo, pela autopercepção terapêutica nesse mundo. Dentro dessa nova moralidade, os velhos ideais de abnegação e transcendência foram substituídos por novos ideais de autorrealização e gratificação imediata. Era o momento do progresso e do presente, do agora. 
Explica Savage (2009), que no impulso para o materialismo, as experiências e desejos dos migrantes internos do país, que fugiam da depressão de uma economia rural em colapso, junto com os imigrantes de segunda geração, libertados do mundo estático europeu de seus pais, foram importantes para a consolidação desses novos valores. $\mathrm{O}$ autor menciona a exposição, "A Cidade Branca" 5 , realizada em 1893, como um marco dessa transição. A partir dela, um novo tipo de visão imaginativa uniria todos os estadunidenses: o senso teatral, o espetáculo, a acumulação e a instantânea satisfação do prazer. Os sonhos acabaram definindo a América e se transformaram em dinheiro, pois se concretizaram em parques temáticos, cinetoscópios, tabloides, livros de sucesso, partituras e em uma abundância de bens de consumo encontrados em lojas de departamento ou catálogos distribuídos pelo correio. Os novos produtos, para Savage (2009: 70), "ofereciam um passo imediato para fora das exigências da realidade cotidiana, um consolo para as liberdades perdidas e uma celebração do estilo de vida metropolitano. A salvação seria encontrada pelo consumo: você se tornava o que comprava". Conforme Savage (2009: 132):

\begin{abstract}
Anunciada pela Expo 1893, a economia do sonho norte-americano começou a se desenvolver como uma importante indústria durante a década de 1900. Transformar a fantasia em dinheiro vivo adequava-se muito bem ao caráter nacional e às exigências de uma nação ainda em formação. Nascida a partir das desesperadas necessidades dos novos imigrantes e desenvolvida por cooperações em processo de consolidação, uma nova cultura de massa foi criada fundindo a psicologia básica humana com as inovações tecnológicas futuristas. Não era apenas uma cultura, mas um novo jeito de ver o mundo que rapidamente se tornou uma força incontrolável.
\end{abstract}

A juventude com suas qualidades, como o bom condicionamento físico e a saúde, eram desejáveis para a sociedade estadunidense. Assim, conforme Savage (2009: 71), a juventude "passou a ser o ideal sedutor para todas as idades". O novo foco coincidiu com o crescimento da psicologia comercial e da indústria cinematográfica que contribuía para a disseminação de novos símbolos para os Estados Unidos.

\footnotetext{
${ }^{5}$ Feira Mundial de Chicago, de 1893. O parque foi planejado pelo arquiteto Daniel Burnham, que colocou a arquitetura em evidência entre os norte-americanos, dando caminho para a ascensão nos EUA de nomes célebres que viriam a seguir, como Frank Lloyd Wright e Mies van der Rohe (ambos com atuação destacada em Chicago).
} 
Wunenburger (2007) menciona os vínculos do imaginário americano (estadunidense, no contexto deste artigo) com o mito matriarcal, que mantêm os indivíduos numa cultura de juventude, na idade infantil, pré-edipiana, protegida dos confrontos com a autoridade e cristalizada numa oralidade primária, dos quais decorrem também os modos alimentares de consumo. O exílio dos colonizadores desta nação se deu com sofrimento e miséria e veio acompanhado de um mito de emancipação. A nova história precisava, então, dar um fim à estrutura europeia. Nesse sentido, os Estados Unidos se constroem com grupos que rejeitam as suas raízes e a rejeição à figura paterna é uma delas. A estrutura patriarcal é amenizada ou mesmo abolida. A figura paterna passa a ser ausente e considerada como cúmplice dos filhos. A fraternidade dos americanos é determinada então pela figura da mãe, supervalorizada como nutridora, encarna a vereda redentora da paz e do amor, símbolo de segurança, em oposição à mulher fatal, fonte de decadência e de ruína.

O imaginário deste povo não integra nenhum verdadeiro herói guerreiro e privilegia um universo imaturo, o dos comics, do Michey, bem como projeta seus afetos no mundo feérico dos animais - Disneyworld -, privilegia também a história em quadrinhos com uma língua regressiva de "balões", de onomatopeias, de monossílabos etc. No mundo de Mickey, dominado pela aspiração à propriedade e à segurança, as personagens Pato Donald, Pateta, Minnie, como exemplos, não vão além de 15 anos de idade, não passam por transformações ou por rituais de iniciação, que sugerem a passagem de uma etapa à outra da vida.

Assim, para o futuro presidente dos Estados Unidos, a construção de uma imagem em torno da juventude, capaz de interagir com esse universo imaturo, o que também pode ser alcançado com recursos de referência às celebridades, aos grandes ídolos do cinema ou da música americana, se faz extremamente pertinente.

A jaqueta de couro, um aspecto referencial potente, com a gola levemente levantada, também nos remete ao rock and roll e a Elvis Presley (Figura 3). Segundo Singer (1985), o rock and roll surgiu nos anos 50 e suas origens estão no blues e na country music. Com um ritmo acelerado, as canções sugeriam ação, velocidade, sexo e lazer agressivo. O filme Breathless mostra o rock vinculado aos jovens trabalhadores, que no sábado à noite, iam para as ruas e nelas deixavam marcas de agressividade e de uma espécie de contestação subjacente à ordem do trabalho semanal, que podia resultar 
em violência pela violência. O protótipo do roqueiro dessa época talvez tenha sido Elvis Presley.

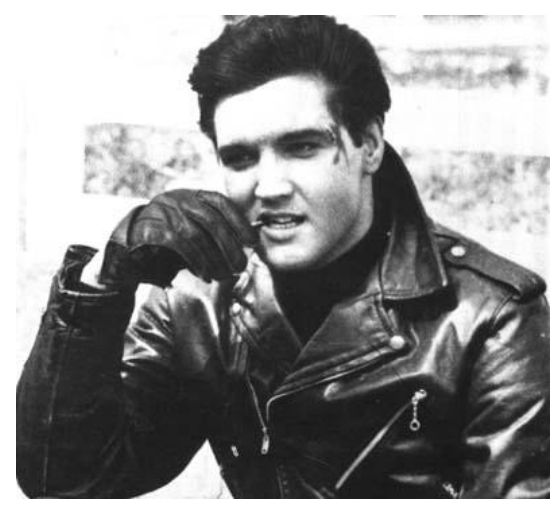

Figura 3 - Reprodução da uma foto de Elvis Presley Fonte - Disponível em:

<http://comadres2ponto0.files.wordpress.com/2012/04/jaquetaperfecto-elvis.jpg>. Acesso em: 10 jun. 2012.

Na década de 1950, o rock vinha com ênfase no sexo, na diversão, bem como na ruptura com a adolescência, o que se deu também por influência das condições do pósguerra. A partir de 1960, segundo Janotti (2003: 21), “a politização do rock está relacionada às condições de produção que envolviam, entre outros fatores, a Guerra do Vietnã e a penetração do rock em ambientes universitários". Ainda, nas palavras de Janotti (2003: 21):

O rock não projeta mais uma vivência totalmente alternativa. A resistência ao modelo econômico e social é dada, antes de tudo, pela possibilidade de vivências em meio ao turbilhão social e econômico contemporâneo, o que permite, aos roqueiros, sobreviver e atravessar as pressões do cotidiano. É um modo de sobrevivência dinâmica, que propicia alguns ancoradouros em meio às certezas da cultura contemporânea.

O contexto construído pelo filme mencionado, bem como o do rock and roll e a sua trajetória se misturam ao contexto da foto de Obama. Os interpretantes podem vir com essa mistura. Os sonhos, as fantasias que vêm com o contexto midiático vinculado à fotografia de Obama fazem com que os novos interpretantes sejam autogerados pelo signo (a imagem fotográfica de Obama). Homem político com ares de ídolo do cinema. Homem político, jovem, capaz de dialogar com a mídia. A juventude agregada à imagem de Obama, considerando-se o aspecto da juventude como um valor altamente 
significativo para a sociedade americana, desde os fins do século XIX, pode tocar o imaginário desta e propiciar o desencadear de novos interpretantes para a foto de Obama, que incorporam a juventude à sua imagem e o legitimam como um representante desta sociedade.

Obama, na foto, nos remete a uma estátua, ao busto de um herói, o que pode gerar interpretantes que atribuem à imagem de Obama a possibilidade de que ele seja visto, antecipadamente, mesmo antes de ser eleito presidente, como um herói da nação. Para Stewart (2003), a estátua era compreendida, desde o final do século XIX e início do XX, como arte pública que implicava funções sociais, como celebração ou honrarias. O valor estético vinha em segundo plano. Durante essa época, o termo estátua era associado sempre a obras públicas, memoriais. Assim, Obama está posto à vista para ser celebrado, honrado. Explica ainda Stewart (2003), que a sociedade romana produziu muitas estátuas e essas tinham suas funções e propósitos. As estátuas podiam estar no lugar de deuses e enquanto representações de divindades, a presença destas se materializava em pedra, madeira, bronze, ouro, prata, mármore. Pelo fato de ser uma representação, a estátua tanto evocava na mente do espectador a potência sagrada, como também estabelecia com a potência sagrada, por meio daquilo que a figura, uma comunicação autêntica. Como representação, a estátua também era a presença vívida do soberano - que podia ser ou não também considerado uma divindade - senão, de uma instituição pública que se quer eterna. A fotografia - pelos aspectos simbólicos mencionados - pode levar o intérprete a considerar Obama como um homem que merece ser celebrado, honrado.

No entanto, se o intérprete se distanciar do que foi fotografado, do que foi capturado pela câmara fotográfica, então, outros aspectos podem guiar a geração de interpretantes. Considerando-se a fotografia como produto de uma máquina e que se destina a uma mídia específica, então ela é portadora de regras, de convenções, de normas específicas tanto advindas da técnica quanto de uma modalidade de produção fotográfica, no caso, para o jornal.

A foto, em questão, se distancia dos padrões usuais do fotojornalismo, pois não se trata de foto-choque e também o referente (o fotografado) é uma figura pública. As reflexões que essas imagens podem provocar, principalmente em intérpretes mais 
familiarizados com as técnicas fotográficas e com as práticas do fotojornalismo, podem levar os profissionais da área a refletirem sobre uma possível tendência que se desenha.

\section{Considerações finais}

De um lado, pela análise apresentada, podemos inferir, possivelmente, que podem ser vinculados à figura pública de Obama, os seguintes atributos: juventude, vivacidade, personagem midiática e enquanto tal capaz de se valer, na construção de sua imagem, de significados que outras mídias disseminam. De outro, o objeto de estudo, não adere às tendências mencionadas para o fotojornalismo, pois é uma foto de uma figura pública, que prima por aspectos qualitativos e referenciais. Com os resultados da análise conjeturamos que fotos com poder de sugestão e de referência, como a apresentada, seriam mais adequadas do que as fotos-choque. Elas propiciam a contemplação, o que vem com o poder de sugestão, bem como possibilitam associações, devido ao poder de referência.

Assim, as fotos com poder de sugestão, que sinalizam sutilmente um acontecimento, se distanciando do mero registro, estariam presentes na nova tendência do fotojornalismo que se desenha. O cunho estético destas fotos é dado pelo poder de sugestão - construído com jogos de cores, formas, texturas - e que levam o intérprete à contemplação. Não se trata de uma estética vazia, portanto.

A contribuição destas reflexões para o fotojornalismo também está na apresentação de uma metodologia de análise para as fotos. Com ela, a interpretação não é fruto de subjetividades, mas da objetividade das qualidades e das pistas presentes na representação visual e que afetam os sentidos e a mente dos possíveis intérpretes. Ao enumerar os aspectos qualitativos, existências ou referencias e os aspectos convencionais tendo a semiótica peirceana como guia, chegamos aos efeitos (ou aos significados) que as fotos podem provocar no intérprete.

Assim, a foto está aí... neste artigo, na internet e em outras mídias e transbordando significados. Nem nosso próprio limite, como intérprete, se exauriu. Se voltarmos o olhar para ela, novamente, certamente novos significados virão à tona. 


\section{Referências}

BARTHES, R. O óbvio e o obtuso. Lisboa: Edições 70, 2009.

DRIGO, M. O. e SOUZA, L. C. P. de. Aulas de semiótica peirceana. São Paulo: Annablume, 2013.

FLUSSER, V. Filosofia da caixa preta: ensaios para uma futura filosofia da fotografia. São Paulo: Huicitec, 1985.

JANOTTI, J. Aumenta aí que isso é rock and roll: mídia, gênero musical e identidade. Rio de Janeiro: E-Papers: Serviços Editoriais, 2003.

MAFFESOLI, M. "O imaginário é uma realidade". Revista Famecos. Porto Alegre, v.1, n. 15, p. 74-81, ago. 2001. Disponível em:

$<$ http://www.revistas.univerciencia.org/index.php/famecos/article/view/285/217>. Acesso em: 05 jan. 2012.

PERSICHETTI, S. A encruzilhada do fotojornalismo. Discursos Fotográficos. Londrina, v. 2, n. 2, p. 179-190, 2006.

SANTAELLA, L. Semiótica Aplicada. São Paulo: Thompson, 2002.

SAVAGE, J. A criação da juventude: como o conceito de teenage revolucionou o século XX. Rio de Janeiro: Rocco, 2009.

SINGER, A. Mudou o rock ou mudaram os roqueiros? Revista de Cultura e Política, São Paulo, v.2, n.1, jun. 1985.

Disponível em: $\quad<$ http://www.scielo.br/scielo.php?pid=S010264451985000200014\&script=sci_arttext $>$. Acesso em: 02 dez. 2011.

SOUSA, J. P. Fotojornalismo: Uma introdução à história, às técnicas e à linguagem da fotografia na imprensa. Porto, 2002.

Contemporâneas, 2000.

Uma história crítica do fotojornalismo ocidental. Florianópolis: Letras

. News values nas "fotos do ano" do World Press Photo: 1956-1996. Porto, 1998.

Disponível em: < www.bocc.ubi.pt>. Acesso em: 10 jan. 2012.

STEWART, P. Statues in roman society. London: Oxford University Press, 2003.

WUNENBURGER, J-J. O imaginário. São Paulo: Edições Loyola, 2007. 